\title{
Effects of Nicotine on Cognitive Deficits in Schizophrenia
}

\author{
Josette G Harris*,', Susan Kongs', Diana Allensworth', Laura Martin ${ }^{1,2}$, Jason Tregellas', \\ Bernadette Sullivan', Gary Zerbe ${ }^{2}$ and Robert Freedman ${ }^{1,3}$ \\ 'Department of Psychiatry, University of Colorado School of Medicine, Denver, CO, USA; ${ }^{2}$ Department of Biometrics and Statistics, University of \\ Colorado School of Medicine, Denver, CO, USA; ${ }^{3}$ Denver Veterans Affairs Medical Center, Denver, CO, USA
}

\begin{abstract}
Several lines of evidence suggest a pathophysiological role for nicotinic receptors in schizophrenia. Activation by nicotine alters physiological dysfunctions, such as eye movement and sensory gating abnormalities, but effects on neuropsychological performance are just beginning to be investigated. Nicotine-induced desensitization and the well-known tachyphylaxis of nicotinic receptors may confound such efforts. In all, 20 schizophrenics, 10 smokers, and 10 nonsmokers were assessed following the administration of nicotine gum and placebo gum. The Repeatable Battery for the Assessment of Neuropsychological Status was administered. Nicotine affected only the Attention Index; there were no effects on learning and memory, language, or visuospatial/constructional abilities. Attentional function was increased in nonsmokers, but decreased in nicotine-abstinent smokers after nicotine administration. The effects of nicotine in schizophrenia do not extend to all areas of cognition. Effects on attention may be severely limited by tachyphylaxis, such that
\end{abstract} decremented performance occurs in smokers, while modest effects may be achieved in nonsmokers.

Neuropsychopharmacology (2004) 29, 1378-1385, advance online publication, 12 May 2004; doi: I 0. I 038/sj.npp. 1300450

Keywords: schizophrenia; neuropsychology; attention; nicotine; nicotinic receptors

\section{INTRODUCTION}

Converging lines of evidence suggest that nicotinic cholinergic receptor agonists should be evaluated for possible therapeutic value in the treatment of schizophrenia. Reduced numbers of nicotinic receptors have been identified in the post-mortem brains of schizophrenic patients compared with controls (Marutle et al, 2001; Guan et al, 1999; Court et al, 1999; Freedman et al, 1995). Adler et al (1993) reported that sensory gating deficits associated with schizophrenia are transiently normalized with the administration of nicotine, and similar findings of normalization by nicotine have been observed for abnormalities in smooth pursuit eye movements (Olincy et al, 1998). Some have suggested that the higher rates of smoking in this population, compared with other psychiatric patients and the general population, may reflect self-medicative behavior (Glassman, 1993). Data from both human and animal studies suggest that nicotinic cholinergic systems in the brain have a role in several cognitive processes as described below, and deficits in cognitive functions associated with these same systems have been identified in patients with

\footnotetext{
*Correspondence: JG Harris, Department of Psychiatry, C268-7I, University of Colorado Health Sciences Center, Denver, CO 80262, USA, Tel: + I 3033154610 , Fax: + I 303315 5347,

E-mail: josette.harris@uchsc.edu

Received 23 August 2003; revised 28 December 2003; accepted 29 January 2004

Online publication: 26 February 2004 at http://www.acnp.org/citations/ Npp02260403386/default.pdf
}

schizophrenia (Braff et al, 1991; Gold et al, 1997; Paulsen et al, 1994). Amelioration of neurocognitive dysfunction is becoming an important focus of clinical treatment development because cognitive deficits are a better predictor of the functional outcome in patients with schizophrenia than are other symptoms of the disease (Meltzer, 1992; Green, 1996; Green and Braff, 2001).

Nicotine administration or cigarette smoking in normals has been shown to improve reaction time (Petrie and Deary, 1989; Hindmarch et al, 1990; Kerr et al, 1991; Sherwood et al, 1992; Pritchard et al, 1992; Bates et al, 1994). Nicotine has also been found to have an effect on performance on tasks measuring alertness and sustained attention (Wesnes and Warburton, 1983; Michel et al, 1987; Hasenfratz et al, 1989; Snyder et al, 1989; Parrott and Craig, 1992; Gilbert et al, 1997; Mancuso et al, 1999, 2001), but fewer studies have reported an effect on tasks that require more elaborated attentional processes or selective attention (Wesnes and Warburton, 1978, 1983; Provost and Woodward, 1991). Effects on verbal memory, aside from immediate recall, which may reflect improved attention, have been studied infrequently.

The few studies that have been conducted of the effect of nicotine on cognition in patients with schizophrenia also identify reaction time and attention as the functions most affected. Levin et al (1996) administered nicotine to patients on differing dosages of haloperidol and found that the haloperidol increased spatial rotation reaction time but nicotine decreased it. There was a decrease in reaction time on a test of attention as well. George et al (2002) found that 
schizophrenics who quit smoking performed worse on a test of sustained attention under a distractor condition, characterized as visuospatial working memory, compared with their baseline performance while smoking; those schizophrenics who continued to smoke maintained their performance over subsequent weeks. Selective attention was not affected. No improvement in verbal memory functions was found in schizophrenic subjects administered nicotine in the Levin et al (1996) study, while better performance on verbal memory tasks was found with the use of nicotine nasal spray compared with placebo spray in another study (Smith et al, 2002). Modest effects on spatial rotation accuracy and reaction time were also found in the Smith et al study. Mancuso et al (2001) have suggested that nicotine acts predominantly upon the posterior attentional system, which may partially explain the findings to date. Indeed, lesions of the basal forebrain cholinergic system in animal studies impair attention, but not learning and memory functions (Muir et al, 1994; Voytko et al, 1994).

In this study, we sought to evaluate whether the administration of nicotine changes cognition in schizophrenia. We were particularly interested in: (1) whether we could effect change in attention processes, given that attention is a core deficit in schizophrenia and given that nicotine enhances attention in normal smokers and nonsmokers, and (2) to what extent, if any, effects would extend to other aspects of cognition. Owing to the marked prevalence of heavy smoking in schizophrenia (Glassman, 1993), the selection of patients for study and the protocol for administering nicotine requires attention to several issues: (1) schizophrenia is thought to be genetically heterogeneous, so that restriction of investigation to nonsmokers may select a group with a pathophysiology that is different from the majority of persons with schizophrenia who smoke, but (2) inclusion of smokers raises the question of how to address the potential confound of their chronic nicotine use. Therefore, in this study, both smokers and nonsmokers were studied, using the protocol described below to minimize withdrawal symptoms in the smokers.

\section{METHODS}

\section{Subjects}

In all, 20 subjects diagnosed with schizophrenia were studied. Of these, 10 subjects were smokers and 10 were nonsmokers, all recruited from the Denver VA and University of Colorado Health Sciences Center outpatient psychiatric clinics. The study was an IRB approved protocol and written informed consent was obtained after a complete description of the study was given to subjects. Diagnosis of schizophrenia was confirmed using either the Structured Clinical Interview for DSM-IV AXIS I Disorders (First et al, 1996) or the Diagnostic Interview for Genetic Studies (Nurnberger et al, 1994). Individuals were excluded from participation if there was any history of neurological illness, significant head trauma, alcohol or substance dependence, or current substance or alcohol abuse. Nonsmokers included seven subjects who had never smoked and three who had been prior smokers. Of the three with prior histories, one last smoked 3 years prior to study participa- tion, one stopped smoking 14 years prior to participation, and the remaining subject had not smoked for 23 years. Smokers were included if they smoked at least 20 cigarettes (on average) per day. The smokers agreed to abstain from smoking for $2 \mathrm{~h}$ prior to and during the testing.

Subjects ranged in age from 33 to 51 years (mean age $=43.9$ years) and education ranged from 9 to 16 years (mean education $=12.9$ years). Of the total sample, $75 \%$ were Caucasian, 15\% Hispanic and 10\% African-American. There were seven male and three female smokers and six male and four female nonsmokers. Seven patients in each group were taking atypical neuroleptics and one patient in each group was taking both a typical and an atypical medication. Table 1 presents clinical demographic data and smoking histories for the 20 participants. Table 2 presents medications for smokers and nonsmokers.

\section{Measures}

In previous studies of physiological deficits associated with schizophrenia, the duration of response to nicotine has been found to be $10-20 \mathrm{~min}$ after nicotine administration, because of nicotine's rapid desensitization of nicotinic receptors (Griffith et al, 1998). The Repeatable Battery for the Assessment of Neuropsychological Status (RBANS; Randolph, 1998) was selected in order to sample a number of neuropsychological domains of function in a brief (30 min or less) period of time. The alternate test versions provided in the RBANS permitted testing on two occasions. The neuropsychological domains assessed by the RBANS are learning and memory, visuospatial/constructional, language, and attention. The RBANS yields five index scores representing these domains. In addition, a total scale score comprised of the index scores is derived. The scores have a mean of 100 and standard deviation of 15 . The index scores, as reported in the test manual, are as follows:

(1) The Immediate Memory Index assesses the ability to learn new verbal material using two separate tasks. The subject is presented with a list of words to memorize over four trials and a narrative story to memorize over two trials.

(2) The Visuospatial/Constructional Index evaluates the ability to copy a figure composed of geometric shapes. In addition, the ability to analyze spatial placement and orientation is examined. The subject is presented with an array of numbered lines. Two lines are presented below the array and the subject is asked to determine which numbered lines have the same orientation as the unnumbered lines.

(3) The Language Index includes a picture naming test and a 1-min word fluency task in which the subject is given a category and asked to produce words that are representative of the category.

(4) The Attention Index is comprised of two tasks. The first is a digit span test in which the subject repeats digits presented orally. The second task is a timed coding test in which the subject is provided with a key that pairs numbers to symbols. The subject is then given a series of symbols and is asked to write the corresponding missing numbers as quickly as possible. 


\section{Effects of nicotine on cognition}

JG Harris et al

Table I Clinical Characteristics and Smoking Status of Subjects

\begin{tabular}{|c|c|c|c|c|c|c|c|}
\hline $\begin{array}{l}\text { Subject } \\
\text { number }\end{array}$ & Subtype & Age (years) & $\begin{array}{c}\text { Age at onset } \\
\text { (years) }\end{array}$ & $\begin{array}{c}\text { Duration of } \\
\text { illness } \\
\text { (years) }\end{array}$ & $\begin{array}{c}\text { Fagerstrom } \\
\text { dependence } \\
\text { score }\end{array}$ & Smoking status & Pack years \\
\hline 2 & Paranoid & 43 & 18 & 25 & 9 & Current & 41 \\
\hline 3 & Paranoid & 47 & 21 & 26 & 4 & Current & 46 \\
\hline 4 & Paranoid & 41 & 27 & 14 & 5 & Current & 28.5 \\
\hline 6 & Disorganized & 45 & 20 & 25 & 5 & Current & 18 \\
\hline 7 & Paranoid & 38 & 21 & 17 & 10 & Current & 68.5 \\
\hline 8 & Paranoid & 51 & 16 & 35 & 7 & Current & 35 \\
\hline 9 & Undifferentiated & 51 & 18 & 33 & 11 & Current & 70 \\
\hline 10 & Paranoid & 41 & 19 & 22 & 7 & Current & 66 \\
\hline 14 & Undifferentiated & 47 & 19 & 28 & - & Never & - \\
\hline 15 & Paranoid & 50 & 28 & 22 & - & Previous & 66 \\
\hline 16 & Paranoid & 47 & 21 & 26 & - & Never & - \\
\hline 17 & Paranoid & 33 & 28 & 5 & - & Never & - \\
\hline 18 & Paranoid & 49 & 24 & 25 & - & Never & - \\
\hline 19 & Disorganized & 33 & 22 & 11 & - & Previous & 0.08 \\
\hline 20 & Paranoid & 40 & 18 & 22 & - & Previous & 0.25 \\
\hline
\end{tabular}

Table 2 Medication Characteristics of Smokers and Nonsmokers

\begin{tabular}{|c|c|c|}
\hline Subject number & Smoking status & Medications \\
\hline I & Smoker & Haloperidol, Benztropin \\
\hline 2 & Smoker & Risperidone, Amitriptyline \\
\hline 4 & Smoker & Olanzapine, Sertraline \\
\hline 5 & Smoker & Olanzapine, Divalproex Sodium \\
\hline 8 & Smoker & Fluphenazine Decanoate, Lithium, Olanzapine \\
\hline 9 & Smoker & $\begin{array}{l}\text { Divalproex Sodium, Perphenazine, Ibuprofen, Diphenhydramine, Norethisterone Acetate/ } \\
\text { Ethinylestradiol }\end{array}$ \\
\hline 10 & Smoker & Clozapine, Sertraline \\
\hline II & Nonsmoker & Loxapine, Benztropine, Ibuprofen, Atenolol \\
\hline 15 & Nonsmoker & Clozapine, Amlodipine, Clonidine, Insulin, Losartan, Fluticasone \\
\hline 16 & Nonsmoker & Olanzapine, Sertraline, Simvastatin \\
\hline 17 & Nonsmoker & Olanzapine, Fluoxetine \\
\hline 18 & Nonsmoker & $\begin{array}{l}\text { Perphenazine, Clonazepam, Quetiapine, Zolpidem, Rosiglitazone, Glimepiride, Ranitidine, Insulin, } \\
\text { Guaifenesin, Fexofenadine, Fluticasone, Conjugated Estrogen/Medroxyprogesterone, Ibuprofen, } \\
\text { Glucosamine sulfate, Vitamins }\end{array}$ \\
\hline 19 & Nonsmoker & Clozapine, Sertraline, Lansoprazole, Docusate Sodium \\
\hline 20 & Nonsmoker & Olanzapine, Lithium \\
\hline
\end{tabular}


(5) The Delayed Memory Index assesses the ability to recall previously learned information presented earlier in the RBANS. The subject is asked to recall the list of words and is also asked to pick out the list words from a longer list of words containing both the target and nontarget words. The subject is required to retell the narrative story and to redraw the geometric figure.

\section{Procedures}

Nicotine abstinence produces disruptions in concentration and performance and changes in mood (US Department of Health and Human Services (USDHHS), 1988). In fact, nicotine withdrawal symptoms, including cognitive and attention deficits, are evident as early as a few hours after the last cigarette is smoked (National Institute on Drug Abuse, 2001; Foulds et al, 1997; Hatsukami et al, 1989; Snyder et al, 1989). It has been argued that nicotinedeprived smokers who show improved performance compared with baseline following the administration of nicotine represents withdrawal relief, rather than any actual performance effect of nicotine (Snyder et al, 1989; West, 1993). In other words, in abstinent smokers, any enhancement in performance may simply represent the restoration of normal (drug-dependent) functioning from a state of abstinence-induced disequilibrium (Heishman et al, 1994). Reports of nicotine withdrawal in psychiatric patients suggest that they may experience more severe withdrawal symptoms than nonpsychiatric patients, and that abstinence may exacerbate their psychopathology (Dalack et al, 1999; Greeman and McClellan, 1991; Glassman et al, 1990; Glassman, 1993; Velasco et al, 1996). Nicotine dependence therefore may represent a different and, perhaps, more severe condition in schizophrenia. For example, George et al (2002) theorized that withdrawal from smoking may lead to alterations in some aspects of cognitive functioning in schizophrenia due to decreases in central dopamine and catecholamine function.

In selecting the optimal period of nicotine deprivation for cognitive studies in schizophrenia, it is essential to note that resensitization of nicotinic receptors in humans is poorly understood. To design a pharmacological study to measure directly resensitization would require the administration of acetylcholine, which cannot be done, or the rapid successive administration of nicotine, which presents an obstacle because of the $2-3 \mathrm{~h}$ half-life of nicotine (Griffith et al, 1998). To further complicate matters, schizophrenics have decreased expression of both high- and low-affinity nicotinic receptors (Leonard et al, 2001), which suggests that resensitization may be different than that in healthy control subjects. Even in controls, there is interindividual variability in the metabolism of nicotine, which could impact resensitization.

After considering these factors, we established a deprivation period of $2 \mathrm{~h}$. This period is consistent with our other studies that have addressed the effects of nicotine on eyetracking (Olincy et al, 1998) and neurocognitive functioning as measured by fMRI (Tregellas et al, 2004). This period of abstinence minimizes the potential withdrawal effects of a longer deprivation period (Warburton, 1990), while still allowing for the detection of an effect attributable to nicotine. Even minimally deprived nonpsychiatric subjects have demonstrated improved reaction time and attention performance following the administration of nicotine in previous studies (Kerr et al, 1991; Warburton and Arnall, 1994). The current study follows the strategy used in the initial studies of the physiological effects of nicotine at the University of Colorado (Adler et al, 1992, 1993). One group of subjects is nonsmoking and the other group is comprised of smokers. The smokers are abstinent for $2 \mathrm{~h}$, so that potential withdrawal symptoms are minimized and so that the experimental administration of nicotine mimics the effect of one of the usual smoking sessions.

The 10 subjects who smoke were monitored for $2 \mathrm{~h}$ prior to and during testing to ensure that they did not smoke during this period. A urine sample to confirm smoking status was obtained from each subject. The urinary analysis was not intended to measure acute nicotine levels, given large interindividual variability in nicotine metabolism. The subject was given either $6 \mathrm{mg}$ of nicotine gum (three $2 \mathrm{mg}$ pieces) or placebo gum to chew for $10 \mathrm{~min}$. Subjects were instructed to chew the gum in 2 min intervals, during which time the gum was intermittently parked in the cheek to aid in mucosal absorption, and the saliva expectorated into a cup. The absorption of nicotine via this method of delivery is rather rapid (see Figure 1). Although, as the figure illustrates, the concentration of nicotine in blood declines rather quickly, there is no evidence that performance correlates with plasma nicotine levels in control subjects (Revell, 1988). This dose of nicotine produces maximal enhancement of P50 inhibition (Adler et al, 1992). Plasma nicotine analysis was not available for this study.

Cognitive testing immediately followed the gum chewing. Subjects were administered the RBANS individually by experienced psychometricians on two occasions, 1 week apart. The RBANS has been demonstrated to have good test-retest reliability in subjects with schizophrenia (Wilk et al, 2002). Both the form of the RBANS (A vs B) and the nicotine condition were balanced across subjects. A second urine sample was obtained at the close of the testing session.

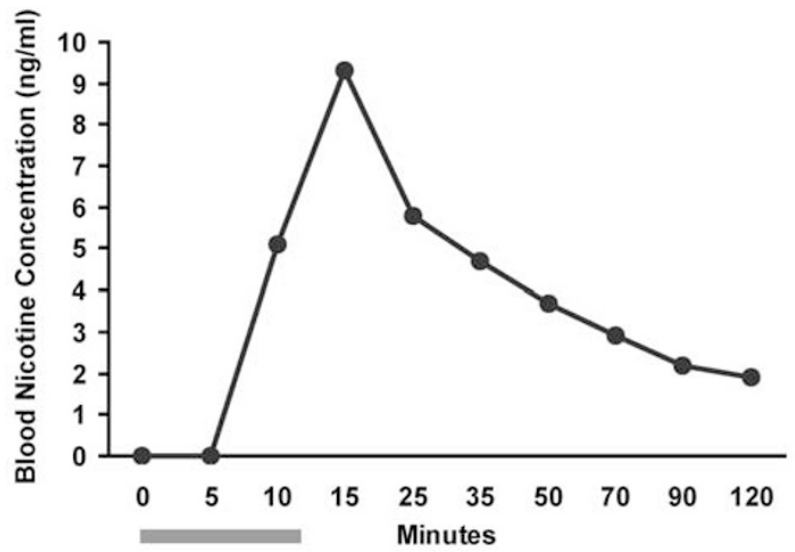

Figure I Plasma nicotine level over $120 \mathrm{~min}$. Blood concentration of nicotine after chewing two $2 \mathrm{mg}$ pieces of nicotine polacrilex gum for I I min. The shaded bar below the $x$-axis represents the time during which the gum was chewed. The subject, a nonsmoker, was instructed to chew the gum for the entire II min and to hold the saliva in his mouth for 2 min intervals, at which point he expectorated into a cup. At 9 min, the subject reported moderate tingling in his mouth, minimal nausea, and sharpened focus. 


\section{RESULTS}

Smokers were significantly less educated than nonsmokers $(t=2.45$, df $1,18, p<0.03)$, as is true of the general population (Centers for Disease Control and Prevention, 2003). Since each subject was his or her own control for the study, no adjustments were made in the analyses for education or for IQ, a variable that tends to correlate highly with education. Comparison of other demographic and clinical variables indicated no significant difference between smokers and nonsmokers with regard to age, age at onset of schizophrenia, or duration of illness.

Pre- and post-test urine nicotine values $(\mathrm{ng} / \mathrm{ml})$ were compared within the two groups using paired sample $t$-tests. Owing to individual differences in metabolism, these values do not reflect acute nicotine levels. Post-test nicotine values under the nicotine condition were not significantly different from baseline in the smokers $(t=1.09, \mathrm{df}=8$, $p>0.30)$. As expected, nicotine values for the nonsmokers under the nicotine condition increased significantly from baseline nicotine levels $(t=-3.05, \mathrm{df}=8, p<0.02)$. Posttest nicotine values under the nicotine condition for nonsmokers were compared to smokers using independent samples $t$-test and found to be significantly lower compared with those of the smokers $(t=3.87, \mathrm{df}=10.96, p<0.004)$.

The mean index scores of attention, immediate memory, delayed memory, visuospatial/ constructional, language, and total score are presented in Table 3 for the two subject groups. The scores were first subjected to a repeated measures ANOVA using SAS statistical software (SAS STAT, Version 8, SAS Institute, Inc., 1999). The fixed factors were groups with two levels (smoking or nonsmoking) and treatment with two levels (nicotine or placebo). The two levels of the treatment factor were considered repeated measurements on each subject. There was a group by treatment interaction effect on the Attention Index $(\mathrm{F}=4.56$, df 1,$18 ; p<0.04)$. Nonsmokers exhibited improved performance on nicotine and smokers demonstrated worsened performance, although neither effect alone was significant in post hoc analyses.

There were no significant group by nicotine effects on the immediate or delayed memory, visuospatial constructional, language, or total index scores. Sequence effects were also entered into the model to analyze for order effects. There were no significant interactions with group or nicotine treatment. Medication effects for typical vs atypical neuroleptics were not analyzed due to the disproportionate numbers of subjects on atypical medications in each group.

\section{DISCUSSION}

Our study found modest effects of nicotine in patients with schizophrenia that were limited to attention and did not extend to other cognitive modalities. Furthermore, the effect was bidirectional: a decline in function in subjects who smoked and an increase in function in those who did not, with neither effect significant by itself. While differences in methodology and test selection limit comparisons, the findings are generally consistent with other neuropsychological studies of nicotine in schizophrenia, which have reported only modest effects. For example, nicotine has been shown to reduce reaction time on tasks involving attention and spatial rotation, and to improve performance on a delayed matching to sample task in schizophrenic patients taking haloperidol (Levin et al, 1996). Nicotine was particularly useful in reversing the cognitive slowing associated with haloperidol in a group of subjects on a medium dose of the drug. Verbal memory performance was neither changed with nicotine gum in our study, with nicotine patch in the Levin et al (1996) study, nor with nicotinized cigarettes in the Smith et al (2002) study; however, in the later investigation, improvement was found with the use of nicotine nasal spray. In another study, patients who quit smoking exhibited worse performance on a test denoted as a visuospatial working memory task compared with baseline performance (George et al, 2002). These results are also consistent with the general clinical impression that nicotine does not significantly improve the clinical symptoms of schizophrenia.

Issues in the assessment of the effects of nicotine in schizophrenia include the possible bias in the selection of smoking or nonsmoking schizophrenics, as well as the effects of neuroleptic medication and pre-existing differences in mental ability. Several of these factors may interact, as patients are more likely to smoke if they are treated with typical antipsychotic medications, as opposed to clozapine

Table 3 Mean RBANS Index, Attention Subtest, and Total Scores for Schizophrenic Smokers and Non-smokers on Placebo and Nicotine Gum Days

\begin{tabular}{|c|c|c|c|c|}
\hline & Smokers placebo & Smokers nicotine & Nonsmokers placebo & Nonsmokers nicotine \\
\hline Coding raw score & $36.7(10.8)$ & $35.2(9.2)$ & $43.3(10.3)$ & $44.6(8.1)$ \\
\hline Digit span raw score & $10.4(2.3)$ & $9.8(1.7)$ & $9.4(2.2)$ & $9.8(2.1)$ \\
\hline Immediate memory & $87.2(21.6)$ & $90.4(15.1)$ & $95.9(19.4)$ & $92.8(13.2)$ \\
\hline Delayed memory & $80.3(19.0)$ & $85.4(16.6)$ & $92.7(15.3)$ & $87.5(13.2)$ \\
\hline Total score & $79.7(\mid 4.0)$ & $80.6(11.6)$ & $89.2(16.3)$ & $88.4(13.0)$ \\
\hline
\end{tabular}

Mean and SD for 10 smokers and 10 nonsmokers.

${ }^{a}$ Repeated measures ANOVA with group (smoking or nonsmoking) and treatment (nicotine or placebo) as fixed factors $\mathrm{F}=4.56$, df I, I8; $p<0.04$. 
(McEvoy et al, 1995, 1999; George et al, 1995); there are interactive neuropsychological effects between neuroleptics and nicotine (Levin et al, 1996); and, less educated persons are more likely to smoke (Centers for Disease Control and Prevention, 2003). Some of these factors, such as type of neuroleptic treatment were controlled in this study by the crossover placebo-controlled design. The issue of a selection bias in studying smokers or nonsmokers presumes that there may be an underlying neurobiological defect that causes some schizophrenics to smoke heavily while others do not. Indeed, there is evidence for smoking behavior as a heritable trait within the psychopathology of schizophrenia. The gene for the alpha7 nicotinic receptor is associated with schizophrenia, but not particularly with smoking behavior (Freedman et al, 1997). However, treatment with clozapine, which increases the release of acetylcholine, has been associated with decreased smoking, including smoking cessation in schizophrenia (McEvoy et al, 1999; George et al, 1995). Thus, the possibility that schizophrenics who do not smoke are different neurobiologically from those who do smoke cannot be ruled out. As schizophrenics who do not smoke are less common than those who do smoke, restriction of the study to nonsmokers might bias the selection towards subjects who would gain little benefit from the activation of nicotinic cholinergic receptors. On the other hand, inclusion of smokers brings up the potentially confounding issues of the presence of residual nicotine from smoking, nicotine withdrawal, and effects of chronic exposure to nicotine. Withdrawal of more than $8 \mathrm{~h}$, which is necessary to eliminate all the nicotine from chronic smoking, introduces the confound of the physiological effects of withdrawal and psychological craving, so that it is not possible to determine to what extent the effects of nicotine are in fact the alleviation of this syndrome (Snyder et al, 1989). Withdrawal of several weeks, which would likely be necessary to eliminate much of the neuroadaptive effects of chronic nicotine exposure, such as the upregulation of nicotinic receptors, requires the selection of schizophrenics who can stop smoking. Nevertheless, both of these strategies have been used successfully by other groups to demonstrate effects of nicotine in schizophrenia (George et al, 2002; Smith et al, 2002).

In studies at the University of Colorado, we have been interested in avoiding as much as possible potential selection bias. Further, we wanted to observe the direct agonist effect of nicotine on nicotinic receptors, as part of our interest in determining whether nicotinic agonist treatment might affect the neurocognition of schizophrenics, and thereby provide a mechanism for new drug development. Therefore, we chose acute administration of nicotine in smokers and nonsmokers. Since we were including nonsmokers, we administered the nicotine in the gum preparation, because we could not ethically expose nonsmokers to tobacco smoke. In smoking cessation, the gum is chewed slowly over $30 \mathrm{~min}$. We increased the rate of chewing and shortened administration to $10 \mathrm{~min}$, which produces a bolus more likely to achieve an agonist effect (Figure 1). For smokers, we chose a short abstinence period, $2 \mathrm{~h}$, so that most subjects could comply, withdrawal symptoms would be minimal, and the nicotine administration would essentially mimic the effect of the next cigarette (Pritchard et al, 1992).
Nicotinic cholinergic receptors were the first receptors demonstrated to develop tachyphylaxis with repeated agonist administration. The effect is exacerbated by the use of nicotine itself as the agonist, because it is not metabolized by acetylcholinesterase, so that it remains bound to the receptors and maintains them in a desensitized state. Individual receptor desensitization occurs within $100 \mathrm{~ms}$ of receptor activation, but tachyphylaxis, the loss of physiological effect at the organ level, requires the desensitization of a population of receptors. This effect occurs over a time period of minutes. For the alpha 7nicotinic receptor, tachyphylaxis is countered by intracellular second messengers, which prolong the effect of receptor activation (Smith et al, 1996). When alpha 7 receptors are activated, calcium influx occurs that activates nitric oxide synthetase. The resultant production of nitric oxide causes physiological changes that persist for up to 30 min. Specifically, the effects of alpha 7-nicotinic receptor activation on inhibitory interneuron mechanisms that underlie auditory sensory gating and the correlated effects on attentional function last for over $20 \mathrm{~min}$, longer than would be predicted from the time course of nicotine blood levels. This prolonged effect is blocked in animal models if the generation of nitric oxide is blocked.

Therefore, in this study, we interpret the effects of nicotine in nonsmokers as representing an agonist effect of nicotine, perhaps dependent on second messengers such as nitric oxide. The time course of study is consonant with the metabolism of nicotine and its prolongation of effect by second messengers. The loss of effect in smokers is consistent with tachyphylaxis caused by chronically high levels of nicotine. The $2 \mathrm{~h}$ of abstinence that they experienced allowed them to excrete some of their nicotine, but not enough to bring levels to zero. Their experience is similar to what they would be expected to have in a job or even an inpatient hospitalization with regular breaks for cigarette smoking. The data suggest that they receive no beneficial effect from nicotine exposure at this interval and that longer intervals are needed before an agonist effect can be re-established. Some workers have suggested that heavy smoking is more consistent with attempts to maintain desensitization than with attempts to achieve repeated agonist effect. However, repeated behaviors such as cigarette smoking can reflect the well-known increased response rate caused by intermittent reinforcement, so that the poor results of heavy smoking do not necessarily clarify its pharmacological motivation. The transdermal nicotine patch is an excellent way to achieve desensitization, because it administers a steady low dose of nicotine that drives receptors to their most stable state, which is the desensitized complex with nicotine. The nicotine patch, however, is not particularly desired by schizophrenics (Dalack et al, 1999). Thus, there is no reason to expect that they naturally prefer the desensitized state. The results of this study suggest that there is no cognitive benefit to remaining in the desensitized state.

The future assessment of the alpha7-nicotinic receptor as a therapeutic target in schizophrenia must take this neurobiology into account. Although desensitization is a problem inherent in the receptor itself, nicotine, which is a toxin evolved to be a desensitizing endogenous insecticide for the tobacco plant, may not be the optimal agonist for 
human use. The limited cognitive effects observed in this study are consistent with the lack of any sustained benefit from smoking for schizophrenics. Other, more specific alpha 7-nicotinic receptor agonists cause significantly less desensitization, and have been reported to produce modest cognitive enhancement in normals (Stevens et al, 1998). Nevertheless, the data in this study indicate that the principal neuropsychological target of nicotinic pharmacologic effects is likely to be the attentional deficits of schizophrenia.

We found a seemingly circumscribed effect of nicotine on attention in our study sample. The selection of a brief screening measure such as the RBANS has limited sensitivity compared to comprehensive neuropsychological batteries, which typically take much longer to administer. As differences between groups may have been minimal to begin with, a comprehensive battery of cognitive measures may have yielded other significant differences. However, given the rapid peak and subsequent decline of nicotine within 20 to $30 \mathrm{~min}$ would mean that the bulk of the assessment measures would be given as plasma nicotine levels were on the decline. Nevertheless, our data are consistent with other data showing that attentional deficits in schizophrenia are transmitted in families independent of both other neuropsychological deficits and clinical symptoms (Harris et al, 1996). We previously compared neuropsychological function in adult schizophrenic probands and their clinically well biological parents. The families were selected to have unilineal ancestral histories of schizophrenia, so that one of the parents was a putative obligate carrier of genetic risk for schizophrenia. We found that the parents who had these positive ancestral histories of schizophrenia had deficits in attention, equal to the deficits in the probands. However, these parents did not share the other cognitive impairments found in the probands, such as impaired learning. Nor did the probands share any of these cognitive deficits with the negative history parents. Thus the attentional deficits in schizophrenia may be independent of other cognitive deficits and perhaps independently affected by nicotinic receptor agonists.

\section{ACKNOWLEDGEMENTS}

This work was supported by USPHS Grants 1RO1 MH59109, 1RO1 MH61412.

\section{REFERENCES}

Adler LE, Hoffer LD, Wiser A, Freedman R (1993). Normalization of auditory physiology by cigarette smoking in schizophrenic patients. Am J Psychiatry 150: 1856-1861.

Adler LE, Hoffer LJ, Griffith J, Waldo MC, Freedman R (1992). Normalization by nicotine of deficient auditory sensory gating in the relatives of schizophrenics. Biol Psychiatry 32: 607-616.

Bates T, Pellett O, Stough C, Mangan G (1994). Effects of smoking on simple and choice reaction time. Psychopharmacology 114 365-368.

Braff DL, Heaton R, Kuck J, Cullum M, Moranville J, Grant I et al (1991). The generalized pattern of neuropsychological deficits in outpatients with chronic schizophrenia with heterogeneous Wisconsin Card Sorting Test results. Arch Gen Psychiatry 48: 891-898.
Centers for Disease Control and Prevention (2003). Number (in millions) of adults 18 years and older who were current, former, or never smokers, overall and by sex, race, Hispanic origin, age, and education, National Health Interview Surveys, selected years-United States, 1965-2000. http://www.cdc.gov/tobacco/ specpop.htm.

Court J, Spurden D, Lloyd S, McKeith I, Ballard C, Cairns N et al (1999). Neuronal nicotinic receptors in dementia with Lewy bodies and schizophrenia: alpha-bungarotoxin and nicotine binding in the thalamus. J Neurochem 73: 1590-1597.

Dalack GW, Becks L, Hill E, Pomerleau OF, Meador-Woodruff JH (1999). Nicotine withdrawal and psychiatric symptoms in cigarette smokers with schizophrenia. Neuropsychopharmacology 21: 195-202.

First MB, Spitzer RL, Gibbon M, Williams JBW (1996). Structured Clinical Interview for DSM-IV Axis I Disorders-Patient edition, (SCID-I/P, version 2.0). Biometrics Research Department, New York State Psychiatric Institute: New York.

Foulds J, Stapleton JA, Bell N, Swettenham J, Jarvis MJ, Russell MAH (1997). Mood and physiological effects of subcutaneous nicotine in smokers and never-smokers. Drug Alcohol Depen 44: 105-115.

Freedman R, Coon H, Myles-Worsley M, Orr-Urtreger A, Olincy A, Davis A et al (1997). Linkage of a neurophysiological deficit in schizophrenia to a chromosome 15 locus. Proc Natl Acad Sci USA 94: 587-592.

Freedman R, Hall M, Adler LE, Leonard S (1995). Evidence in postmortem brain tissue for decreased numbers of hippocampal nicotinic receptors in schizophrenia. Biol Psychiatry 38: 22-33.

George TP, Sernyak MJ, Ziedonis DM, Woods SW (1995). Effects of clozapine on smoking in chronic schizophrenic outpatients. J Clin Psychiatry 56: 344-346.

George TP, Vessicchio JC, Termine A, Sahady DM, Head CA, Pepper WT et al (2002). Effects of smoking abstinence on visuospatial working memory function in schizophrenia. Neuropsychopharmacology 26: 75-85.

Gilbert DG, Estes SL, Welser R (1997). Does noise stress modulate effects of smoking/nicotine? Mood, vigilance, and EEG responses. Psychopharmacology 129: 382-389.

Glassman AH (1993). Cigarette smoking: implications for psychiatric illness. Am J Psychiatry 150: 546-553.

Glassman AH, Helzer JE, Covey LS, Cottler LB, Stetner F, Tipp JE et al (1990). Smoking, smoking cessation, and major depression. JAMA 264: 1546-1549.

Gold JM, Carpenter C, Randolph C, Goldberg TE, Weinberger DR (1997). Auditory working memory and Wisconsin Card Sorting Test performance in schizophrenia. Arch Gen Psychiatry 54: $159-165$.

Greeman M, McClellan TA (1991). Negative effects of a smoking ban on an inpatient psychiatry service. Hosp Comm Psychiatry 42: 408-412.

Green MF (1996). What are the functional consequences of neurocognitive deficits in schizophrenia? Am J Psychiatry 153: 321-330.

Green MF, Braff D (2001). Translating the basic and clinical cognitive neuroscience of schizophrenia to drug development and clinical trials of antipsychotic medications. Biol Psychiatry 49: $374-384$.

Griffith JM, O'Neill JE, Petty F, Garver D, Young D, Freedman R (1998). Nicotinic receptor desensitization and sensory gating deficits in schizophrenia. Biol Psychiatry 44: 98-106.

Guan ZZ, Zhang X, Blennow K, Nordberg A (1999). Decreased protein level of nicotinic receptor alpha7 subunit in the frontal cortex from schizophrenic brain. Neuroreport 10: 1779-1782.

Harris JG, Adler LE, Young DA, Cullum CM, Rilling LM, Cicerello A et al (1996). Neuropsychological dysfunction in parents of schizophrenics. Schizophr Res 20: 253-260. 
Hasenfratz M, Michel C, Nil R, Bättig K (1989). Can smoking increase attention in rapid information processing during noise? Electrocortical, physiological and behavioral effects. Psychopharmacology 98: 75-80.

Hatsukami DK, Fletcher L, Morgan S, Keenan R, Amble P (1989). The effects of varying cigarette deprivation duration on cognitive and performance tasks. J Subst Abuse 1: 407-416.

Heishman SJ, Taylor RC, Henningfield JE (1994). Nicotine and smoking: a rewiew of effects on human performance. Experimental and Clinical Psychopharmacology 2: 345-395.

Hindmarch I, Kerr JS, Sherwood N (1990). Effects of nicotine gum on psychomotor performance in smokers and non-smokers. Psychopharmacology 100: 535-541.

Kerr JS, Sherwood N, Hindmarch I (1991). Separate and combined effects of the social drugs on psychomotor performance. Psychopharmacology 104: 113-119.

Leonard S, Adler LE, Banhammou K, Berger R, Breese CR, Drebing C et al (2001). Smoking and mental illness. Pharmacol Biochem Behav 70: 561-570.

Levin ED, Wilson W, Rose J, McEvoy J (1996). Nicotinehaloperidol interactions and cognitive performance in schizophrenics. Neuropsychopharmacology 15: 429-436.

Mancuso G, Lejeune M, Ansseau M (2001). Cigarette smoking and attention: processing speed or specific effects? Psychopharmacology 155: 372-378.

Mancuso G, Warburton DM, Melen M, Sherwood N, Tirelli E (1999). Selective effects of nicotine on attentional processes. Psychopharmacology 146: 199-204.

Marutle A, Zhang X, Court J, Piggott M, Johnson M, Perry R et al (2001). Laminar distribution of nicotinic receptor subtypes in cortical regions in schizophrenia. J Chem Neuroanat 22: $115-126$.

McEvoy JP, Freudenreich O, Levin ED, Rose JE (1995). Haloperidol increases smoking in patients with schizophrenia. Psychopharmacology 119: 124-126.

McEvoy JP, Freudenreich O, Wilson WH (1999). Smoking and therapeutic response to clozapine in patients with schizophrenia. Biol Psychiatry 46: 125-129.

Meltzer HY (1992). Dimensions of outcome with clozapine. $\mathrm{Br}$ J Psychiatry 160: 46-53.

Michel C, Nil R, Buzzi R, Woodson PP, Battig K (1987). Rapid information processing and concomitant event-related brain potentials in smokers differing in $\mathrm{CO}$ absorption. Neuropsychobiology 17: 161-168.

Muir JL, Everitt BJ, Robbins TW (1994). AMPA-induced excitotoxic lesions of basal forebrain: A significant role for the cortical cholingeric system in attentional function. J Neurosci 14: 2313-2326.

National Institute on Drug Abuse (2001). Research Report Series-Nicotine Addiction, (On line). Available internet: www.drugabuse.gov/ResearchReports/Nicotine/nicotine3.html.

Nurnberger Jr JI, Blehar MC, Kaufmann CA, York-Cooler C, Simpson SG, Harkavy-Friedman J et al (1994). Diagnostic interview for genetic studies. Rationale, unique features, and training. NIMH Genetic Initiative. Arch Gen Psychiatry 51: 849-859; (discussion 863-864).

Olincy A, Ross RG, Young DA, Roath M, Freedman R (1998). Improvement in smooth pursuit eye movements after cigarette smoking in schizophrenic patients. Neuropsychopharmacology 18: $175-185$.

Parrott AC, Craig D (1992). Cigarette smoking and nicotine gum ( 0,2 and $4 \mathrm{mg})$ : effects upon four visual attention tasks. Neuropsychobiology 25: 34-43.

Paulsen JS, Heaton RK, Sadek JR, Perry W, Delis DC, Braff D et al (1994). The nature of learning and memory impairments in schizophrenia. J Int Neuropsychol Soc 1: 88-99.
Petrie R, Deary T (1989). Smoking and human information processing. Psychopharmacology 99: 393-396.

Pritchard WS, Robinson JH, Guy TD (1992). Enhancement of continuous performance task reaction time by smoking in nondeprived smokers. Psychopharmacology 108: 437-442.

Provost SC, Woodward R (1991). Effects of nicotine gum on repeated administration of the Stroop test. Psychopharmacology 104: 536-540.

Randolph C (1998). Repeatable Battery for the Assessment of Neuropsychological Status. The Psychological Corporation: San Antonio.

Revell AD (1988). Smoking and performance: a puff-by-puff analysis. Psychopharmacology 96: 563-565.

SAS Institute Inc (1999). SAS/STATC User's Guide, Version 8. SAS Institute: Cary, NC. 3884pp.

Sherwood N, Kerr JS, Hindmarch I (1992). Psychomotor performance in smokers following single and repeated doses of nicotine gum. Special issue: nicotine. Psychopharmacology 108: 432-436.

Smith DA, Hoffman AF, David DJ, Adams CE, Gerhardt GA (1996). Nicotine-evoked nitric oxide release in the rat hippocampal slice. Neurosci Lett 255: 127-130.

Smith RC, Singh A, Infante M, Khandat A, Kloos A (2002). Effects of cigarette smoking and nicotine nasal spray on psychiatric symptoms and cognition in schizophrenia. Neuropsychopharmacology 27: 479-497.

Snyder PR, Davis FC, Henningfield JE (1989). The tobacco withdrawal syndrome: Performance decrements assessed on a computerized test battery. Drug Alcohol Depend 23: 259-266.

Stevens K, Kem WR, Mahnir VM, Freedman R (1998). Selective alpha7-nicotinic agonists normalize inhibition of auditory response in DBA mice. Psychopharmacology 136: 320-327.

Tregellas JR, Tanabe JL, Martin LF, Freedman R (2004). fMRI of response to nicotine during a smooth pursuit eye movement task in schizophrenia (under review).

US Dept. of Health and Human Services (1988). The Health Consequences of Smoking: Nicotine Addiction: A Report of the Surgeon General, US Department of Heal and Human Services, Centers for Disease Control and Prevention, National Center for Chronic Disease Prevention and Health Promotion, Office on Smoking and Health: Atlanta, GA 383-413.

Velasco J, Eells TD, Anderson R, Head M, Ryabik B, Mount R et al (1996). A two-year follow-up on the effects of a smoking ban in an inpatient psychiatric service. Psychiatric Serv 47: 869-871.

Voytko ML, Olton DS, Richardson RT, Gorman LK, Tobin JT, Price DL (1994). Basal forebrain lesions in monkeys disrupt attention but not learning and memory. J Neurosci 14: 167-186.

Warburton DM (1990). Pharmacological aspects of nicotine. In Wonnacott S, Russell MAH, Stolerman IP (eds). Nicotine Psychopharmacology: Molecular, Cellular and Behavioural Aspects. Oxford University Press: Oxford.

Warburton DM, Arnall C (1994). Improvements in performance without nicotine withdrawal. Psychopharmacology 115: 539-542.

Wesnes K, Warburton DM (1978). The effects of cigarette smoking and nicotine tablets upon human attention. In Thornton RE (ed). Smoking Behaviour: Physiological and Psychological Influences. Churchill-Livingstone: London. pp 131-147.

Wesnes K, Warburton DM (1983). Smoking, nicotine and human performance. Pharmacol Ther 21: 189-208.

West R (1993). Beneficial effect of nicotine: fact or fiction? (Editorial). Addiction 88: 589-590.

Wilk CM, Gold JM, Bartko JJ, Dickerson F, Fenton WS, Knable M et al (2002). Test-retest stability of the Repeatable Battery for the Assessment of Neuropsychological Status in schizophrenia. Am J Psychiatry 159: 838-844. 